\title{
Depressive symptoms among Chinese residents: how are the natural, built, and social environments correlated?
}

\author{
Ruoyu Wang ${ }^{1,2}$, Ye Liu ${ }^{1,2^{*}}$, Desheng Xue $e^{1,2^{*}}$ and Marco Helbich ${ }^{3}$
}

\begin{abstract}
Background: Depression has become a severe societal problem in China. Although many studies have analyzed how environmental characteristics within neighborhoods affect depression, only a few have dealt with developing countries, and even fewer have considered built, natural, and social environments concurrently.

Methods: Based on a sample of 20,533 Chinese residents assessed in 2016, the present study examined associations between depressive symptoms and respondents' built, natural, and social environments. Depressive symptoms were measured using the Center for Epidemiologic Studies Depression Scale (CES-D), and multilevel regression models were fitted accounting for potential covariates.

Results: Results indicated that living in neighborhoods with more green spaces and a higher population density were negatively associated with CES-D scores. Living in neighborhoods with more social capital was protective against depression. Furthermore, results showed that the social environment moderated the association between the built environment and depression.

Conclusions: Social environments moderate the relationship between the built environment and depression. As environments seem to interact with each other, we advise against relying on a single environment when examining associations with depressive symptoms.
\end{abstract}

Keywords: Depression, Built, natural, and social environments, Moderating effect, China

\section{Background}

The prevalence of depressive symptoms is a serious societal challenge in China. The most recent China Health and Retirement Longitudinal Study [1] showed that depressive disorders are widespread across the population (lifetime prevalence is approximately $25 \%$ ).

Significant efforts have been made to unravel risk and protective factors for depression. In the past, for instance, the emphasis was primarily on individual determinants, such as gender, age, psychological conditions, etc., but research interest has shifted towards the contribution of environmental characteristics [2,3]. There are diverse environments, including natural environments (e.g., green spaces such as parks and forests; blue spaces

\footnotetext{
* Correspondence: liuye25@mail.sysu.edu.cn; eesxds@mail.sysu.edu.cn ${ }^{1}$ School of Geography and Planning, Sun Yat-Sen University, Xingang Xi Road, Guangzhou 510275, China
}

Full list of author information is available at the end of the article such as lakes and rivers) [4-7], environmental hazards (e.g., noise and air pollution) $[8,9]$, built environments (e.g., urban form) [10, 11], and social environments (which encompasses social relationships and cultural milieus within which people interact) [12] that could influence depressive symptoms. When investigating risk and protective factors for depression, it is likely that environmental factors are at play [13]. Although environmental exposures occur elsewhere (e.g., in the workplace) [14], immediate residential context is central to people's daily activities, thereby playing an important role in affecting depression risk [15-24].

Findings addressing the contribution of environmental factors on depression are not consistent across studies. This is at least partly due to the following reasons. First, previous studies on the link between environmental factors and depression mainly focus on one specific environmental category (i.e., the natural environment, 
environmental hazards, the built environment, or the social environment) instead of multiple categories. For example, a recent cross-sectional, ecological study explored the impact of green spaces on depression, without taking the social environment into account [25]. This may lead to omitted variable bias, namely that relevant variables are missing from the model while having a significant influence on the mental health outcome.

Second, the majority of previous studies are limited to the direct health effect of environmental factors and disregard the fact that different categories of environmental factors may interact with each other. It is plausible that different environmental factors enhance health benefits or alleviate negative health threats [24]. For instance, it remains largely unclear whether the social environment moderates the relationship between the natural and the environment on mental health [26, 27]. Some studies have noted that the social characteristics of a neighborhood can moderate the relationship between residents' built and/or natural environment on depressive symptoms [13, 28]. Wang et al., for example, found that neighborhood social capital played a role in weakening the effect of air pollution on depressive symptom risk [13]. Nevertheless, whether a neighborhood's social environment also moderates the relationship between residents' depressive symptoms and the built and natural environment is still unknown and needs further investigation.

The present study addressed these significant knowledge gaps by investigating the extent to which the built environment, the natural environment, and the social environment are associated with depression risk in China. We paid special attention to interdependencies between the social environment, the natural environment, and the built environments in shaping residents' depressive symptoms. The structure of this paper is as follows. The following section provides some background information regarding the study sample, data, and methods. Our statistical results are then presented and embedded in current debates. Finally, the paper concludes with a brief summary of key findings.

\section{Methods}

\section{Study sample}

This study utilized a cross-sectional design based on nationally representative data from China. We used survey data from the 2016 wave of the China Labor-force Dynamics Survey (CLDS). In this survey, respondents were sampled using a multistage, cluster, stratified, probability proportional to size sampling technique. The sampling procedure was conducted as follows. First, the survey team chose 158 prefecture-level divisions in 29 provinces in a random fashion. Prefecture-level divisions are the secondary administrative divisions and include prefectures, prefecture-level cities, and leagues. Second, 394 neighborhoods were randomly chosen from the prefecture-level divisions. Third, 14,226 households were randomly chosen from the neighborhood-level divisions. Household members who were aged between 15 and 64, and who were aged above 64 but were involved in the labor force, entered the sample. The response rate was $86.15 \%$ (91.35\% for rural areas and $80.20 \%$ for urban areas). After omitting cases with missing data and invalid questionnaires $(n=$ 328), our final sample included 20,533 people living in 394 neighborhoods.

\section{Data}

\section{Dependent variable}

The outcome variable was experienced symptoms associated with depression, assessed with the Center for Epidemiologic Studies Depression Scale (CES-D). The CLDS questionnaire contains a CES-D scale, and all respondents were invited to complete this measure. The CES-D comprises 20 items and is designed to measure the mental state of residents over the previous week (i.e., feeling alone, feeling disliked, and people being unfriendly) [29]. The CES-D score ranges from 0 to 60 , with higher values indicating higher depressive symptoms. The CES-D has been shown to have good validity and reliability within Chinese samples [30].

The Cronbach's alpha of 0.95 on the CES-D suggested excellent internal consistency of the measure within the current sample. Concurrent validity was evaluated by examining factor loadings from a confirmatory factor analysis. All factor (item) loadings were greater than 0.50 and significant at the 0.05 level, indicating that the CES-D had adequate concurrent validity. The average variance extracted from each item was greater than the squared correlation coefficients between items, suggesting adequate discriminant validity. To produce a more normally distributed CES-D score, we applied a log transformation before the variable was included in the regression analyses.

\section{The natural outdoor environment}

The CLDS also contains questions about both individual attributes and the environmental characteristics of the community. As for the natural outdoor environment, we considered residents' exposure to green spaces in the analyses, which was measured by the percentage of greenery coverage within the neighborhood. Specifically, trained auditors were hired by the CLDS survey team to measure residents' exposure to green spaces based on the digital map of each neighborhood [25]. We assumed that people who were more exposed to green spaces would have fewer depression symptoms [31]. 


\section{The built environment}

The built environment was operationalized in two ways. As the prevalence of psychiatric disorders tends to vary across urban and rural areas [32], we considered urbanicity in our analyses. Urbanicity was operationalized as the population density measured by the number of people per unit area. We assumed a positive correlation between neighborhood population density and urbanicity. The presence of sports facilities within a neighborhood has been noted to lower the risk of mental disorders through the encouragement of physical activities [33]. Thus, we used a dummy variable to capture the existence of sports facilities within the neighborhood.

\section{The social environment}

Five variables were used to capture quality of the neighborhood social environment, which was aggregated from individuals to the neighborhood level. We used social trust, social reciprocity, and social group membership to measure neighborhood social capital $[34,35]$. Social trust is part of the CLDS survey and was measured as the proportion of residents within a neighborhood who reported that people living in the neighborhood were trustworthy. Neighborhood-based social reciprocity was quantified by the proportion of residents within a neighborhood who found their neighbors supportive and were willing to help each other. Social group membership was measured by the proportion of residents within a neighborhood who belonged to at least one of the following social groups: ju wei hui (residents' committee), social work organization, homeowners' association, leisure/sports group, tong xiang hui (townsman association), clan organization, volunteer organization, and religious groups. To quantify the level of inequality in the average annual household income per household member, we calculated the Gini index [26, 36]. An index of 0 refers to equal distribution of income, while 1 refers to maximum income inequality. Finally, we considered neighborhood security, assuming that respondents living in insecure areas were more likely to experience depressive symptoms [26]. This variable was operationalized as the proportion of residents within a neighborhood who reported that their neighborhood was safe.

\section{Covariates}

Following previous studies [2, 3], we adjusted for a series of individual-level and neighborhood-level covariates. These covariates were gender, age, marital status, educational attainment, employment status, hukou status, living area, smoking history, drinking history, medical insurance status, physical health condition, neighbourhood type (urban and rural), individual-level social capital (trust, reciprocity, and social group membership), individual sense of security, annual household income per capita, and annual neighborhood income per neighborhood resident.

\section{Statistical analyses}

Summary statistics were used to describe the data. As regression assumptions are challenged by multicollinearity, we used variance inflation factors (VIF) to test for this possibility. VIF scores larger than three indicate suspicious correlations among covariates. Based on the VIF scores in this study $(<3)$, we found no evidence that multicollinearity among variables was an issue. Subsequently, we assessed the associations between CES-D scores and the environmental variables. Due to the hierarchical structure of data, whereby people are nested in neighborhoods, it was necessary to apply multilevel modeling [37] to avoid biasing the model output. The intra-class correlation coefficient of the null model (i.e., 0.17) showed that CES-D scores within the same neighborhood were somewhat correlated, confirming the application of multilevel models.

A set of multilevel models with different levels of complexity were fitted. Our null model (i.e., one without covariates) quantified the degree of intra-class correlations across neighborhoods. Our baseline model (Model 1) assessed the correlations between CES-D scores and the environmental variables while adjusting for the covariates. Next, cross-level interactions were added to Model 1 to identify whether the social environment moderated the relationship between the built and the natural environment, as well as respondents' depression level (Models $2-4)$. These models were fitted with a random intercept per neighborhood. To compare the quality of these models, we employed the Akaike information criterion (AIC). Lower AIC scores indicate better model fit. All continuous independent variables were mean centered.

\section{Results}

Summary statistics for all variables are presented in Table 1. The mean CES-D score for all respondents was 7.28 , with a standard deviation of 9.26.

Table 2 shows the estimation results for all regression models. Starting with Model 1, which considered the main effects only, CES-D scores were significantly related with the quality of the natural, the built, and the social environment. Specifically, green spaces [Coef. $=-0.045, \mathrm{SE}=0.023]$ and urbanicity (i.e., logged population density) [Coef. $=-0.042, \mathrm{SE}=$ 0.015] were inversely related to CES-D scores. Social trust [Coef. $=-0.407, \mathrm{SE}=0.205]$, reciprocity [Coef. $=$ $-0.286, \mathrm{~S} \mathrm{E}=0.120$ ], and group membership [Coef. = $-0.404, \quad \mathrm{SE}=0.159]$ were consistently negatively 
Table 1 Summary statistics of the variables

\begin{tabular}{|c|c|c|}
\hline & Proportion & Mean (SD) \\
\hline \multicolumn{3}{|l|}{ Variable } \\
\hline CES-D score & & $7.28(9.26)$ \\
\hline \multicolumn{3}{|l|}{ Natural environment of the neighborhood } \\
\hline Green space (\%) & & $49.73(27.29)$ \\
\hline \multicolumn{3}{|l|}{ Built environment of the neighborhood } \\
\hline Urbanicity (people/km²) & & $29,625.05(415,537.75)$ \\
\hline Sports facilities (yes, no) & $66,34 \%$ & \\
\hline \multicolumn{3}{|l|}{ Social environment of the neighborhood } \\
\hline Social trust & & $0.78(0.12)$ \\
\hline Social reciprocity & & $0.48(0.23)$ \\
\hline Social group membership & & $0.08(0.15)$ \\
\hline Gini index of household income & & $0.43(0.10)$ \\
\hline Security & & $0.91(0.10)$ \\
\hline \multicolumn{3}{|l|}{ Covariates at the individual level } \\
\hline Gender (male, female) & $47,53 \%$ & \\
\hline Age (years) & & $44.81(14.61)$ \\
\hline \multicolumn{3}{|l|}{ Marital status } \\
\hline Single, divorced, or widowed & $19 \%$ & \\
\hline Married - living with spouse & $73 \%$ & \\
\hline Married - not living with spouse & $8 \%$ & \\
\hline \multicolumn{3}{|l|}{ Educational attainment level } \\
\hline Primary school or lower & $35 \%$ & \\
\hline High school & $52 \%$ & \\
\hline College or higher & $13 \%$ & \\
\hline Employment (employed, unemployed) & $95,5 \%$ & \\
\hline Hukou status (local hukou, non-local hukou) & $91,9 \%$ & \\
\hline Smoker (yes, no) & $27,73 \%$ & \\
\hline Alcohol use (yes, no) & $19,81 \%$ & \\
\hline Medical insurance (yes, no) & $90,10 \%$ & \\
\hline Physical health status (good, bad) & $90,10 \%$ & \\
\hline $\begin{array}{l}\text { Neighbourhood type (urban } \\
\text { neighbourhood, rural neighbourhood) }\end{array}$ & $38,62 \%$ & \\
\hline Social trust (trustworthy, not trustworthy) & $22,78 \%$ & \\
\hline $\begin{array}{l}\text { Social reciprocity (people often help each } \\
\text { other, seldom/never) }\end{array}$ & $48,52 \%$ & \\
\hline $\begin{array}{l}\text { Social group membership (number of } \\
\text { social groups) }\end{array}$ & & $0.08(0.37)$ \\
\hline Sense of safety (safe, unsafe) & $91,9 \%$ & \\
\hline $\begin{array}{l}\text { Average annual household income per } \\
\text { household member (CNY) }\end{array}$ & & $18,010.46(204,076.28)$ \\
\hline $\begin{array}{l}\text { Average annual neighborhood income per } \\
\text { neighborhood resident (CNY) }\end{array}$ & & $17,826.38(32,388.29)$ \\
\hline
\end{tabular}

related to CES-D scores. These correlations were statistically significant. No evidence showed that availablity of sports facilities, security or Gini index was associated with CES-D scores. The majority of covariates revealed the expected results, and their relationships with depression were, with a few exceptions, statistically significant. No evidence was found for
Table 2 Results of the multilevel regressions

\begin{tabular}{|c|c|c|}
\hline \multirow[t]{2}{*}{ DV: Logged CES-D score } & \multicolumn{2}{|l|}{ Model 1} \\
\hline & Coefficients & Standard error \\
\hline \multicolumn{3}{|l|}{ Natural environment of the neighborhood } \\
\hline Logged green space & $-0.045^{*}$ & 0.023 \\
\hline \multicolumn{3}{|l|}{ Built environment of the neighborhood } \\
\hline Urbanicity & $-0.042^{* *}$ & 0.015 \\
\hline Sports facilities (ref: no) & -0.001 & 0.044 \\
\hline \multicolumn{3}{|l|}{ Social environment of the neighborhood } \\
\hline Social trust & $-0.407^{*}$ & 0.205 \\
\hline Social reciprocity & $-0.286^{*}$ & 0.120 \\
\hline Social group membership & $-0.404^{*}$ & 0.159 \\
\hline Gini index of household income & 0.209 & 0.195 \\
\hline Security & 0.325 & 0.217 \\
\hline \multicolumn{3}{|l|}{ Covariates } \\
\hline Male (ref: female) & $-0.190^{* *}$ & 0.019 \\
\hline Age & $0.003^{* *}$ & 0.001 \\
\hline \multicolumn{3}{|l|}{ Marital status (ref: single, divorced, widowed) } \\
\hline Married - living with spouse & $-0.116^{* *}$ & 0.022 \\
\hline Married - not living with spouse & $-0.100^{* *}$ & 0.033 \\
\hline \multicolumn{3}{|l|}{ Educational level (ref: primary school or lower) } \\
\hline High school & $-0.134^{* *}$ & 0.019 \\
\hline College or higher & $-0.098^{* *}$ & 0.031 \\
\hline Employed (ref: unemployed) & $-0.101^{* *}$ & 0.033 \\
\hline Local hukou (ref: non-local hukou) & $-0.063^{*}$ & 0.031 \\
\hline Smoker (ref: no) & 0.015 & 0.022 \\
\hline Alcohol use (ref: no) & $0.047^{*}$ & 0.021 \\
\hline Medical insurance (ref: no) & -0.036 & 0.025 \\
\hline Physical health status (ref: good) & $0.674^{* *}$ & 0.025 \\
\hline Urban neighbourhood (ref: rural neighbourhood) & $0.116^{*}$ & 0.058 \\
\hline Logged household income per capita & $-0.061^{* *}$ & 0.008 \\
\hline Social trust (ref: not trustworthy) & $-0.212^{* *}$ & 0.019 \\
\hline Social reciprocity (ref: people seldom/never help) & $-0.120^{* *}$ & 0.017 \\
\hline Number of social groups & $-0.384^{* *}$ & 0.033 \\
\hline Sense of security (ref: unsafe) & $-0.200 * *$ & 0.027 \\
\hline Logged community income per capita & $-0.080^{* *}$ & 0.058 \\
\hline Constant & $3.971^{* *}$ & 0.345 \\
\hline Var. (constant) & $0.128^{* *}$ & \\
\hline Var. (residual) & $1.074^{* *}$ & \\
\hline AIC & $60,554.29$ & \\
\hline
\end{tabular}

Significance level: ${ }^{*} p<0.05,{ }^{* *} p<0.01$. All continuous independent variables were mean centered

either smoking or medical insurance being associated with CES-D scores at the $5 \%$ significance level.

Models 2-4 extended the baseline model by adding cross-level interaction terms between the significant neighborhood-level environmental variables. In general, the results indicated that the social environment can either strengthen or weaken the natural environment-depression relationship, as well as the built environment-depression 
relationship. Model 2 showed that neighborhood-based social capital strengthened the relationships between green spaces and CES-D scores. The income-based Gini index weakened the association between green spaces and CES-D scores. Model 3 showed that both social capital and a sense of security strengthened the relationship between urbanicity and CES-D scores. In contrast, the Gini index of income weakened the relationship between urbanicity and CES-D scores. Similarly, Model 4 indicated that social capital strengthened the relationship between the presence of sports facilities and CES-D scores, while the income-based Gini index weakened the association between the presence of sports facilities and CES-D scores (Table 3).

\section{Discussion}

The present study examined how the quality of neighborhood natural, built, and social environments influence depression across China. By exploring interactions between these environments, we have made a contribution to the literature.

Across all models, we observed that the quality of natural, built, and social environments is associated with respondents' depressive symptoms. Regarding the natural environment, our findings indicated that more green space availability per neighborhood was positively associated with residents' mental health. This finding is in accordance with previous studies [16, 18, 20-22, 25]. Reasonable explanations are that green spaces may increase people's physical activity levels [38], encourage social contacts among neighbors [39], reduce stress [6, 8], and reduce environmental hazards, including air pollution and noise $[6,8]$.

Urbanicity was negatively associated with depressive symptoms, as found by other researchers $[17,23]$. It may be that people living in a neighborhood with a higher population density are more likely to have frequent and intense contacts with neighbors and friends, both of which are known to be beneficial to mental health [17, 23]. Higher urbanicity may also be associated with better medical resources [40], so that residents living in more urban neighborhoods are likely to have better access to mental healthcare. Not in line with other studies [15, 19], that the availability of sports facilities was not associated with depressive symptoms. As confirmed by a review of previous literature [33], physical activity is a central factor in reducing the risk for depression onset or mitigating depressive symptoms. However, most respondents in our study are from rural areas, so they are more likely to have manual activity during work time and will not use sports facilities during leisure time.

We also observed that social capital was negatively associated with depression [36, 41-43], indicating that neighborhood social capital has mental health protective benefits. Only a few Chinese studies suggest that residents of neighborhoods with more social capital receive more social support from their neighbors, increasing one's ability to cope with stress and life difficulties [44, 45]. However, neighborhood-based Gini index for income and neighborhood security had no association with mental health which is inconsistent with previous studies [27, 36]. Other Chinese studies found that income inequality increases the risk for both physical and mental disorders, as people from diverse income groups are more likely to come into conflict with each other, potentially creating a stressor that could facilitate the development of depressive symptoms [46, 47] but compared with previous studies in China, this study have much more rural respondents who may not be that sensitive to income inequality which may explain the insignificant association in terms of neighborhood security, our results is inconsistent with earlier findings from developed countries $[26,27]$. This may be also because rural residents in China are not that sensitive to neighbourhood security [48].

Most importantly, the present study revealed that the social environment moderates the relationship between the built environment and depression. Regarding green space availability per neighborhood, results indicated that social capital strengthened the positive relationship between green spaces and residents' mental health. This might be because people living in a neighborhood with pronounced social capital are more likely to be willing to share open spaces with each other or to undertake physical activities together [49], strengthening the effects of green spaces. In contrast, residents of neighborhoods with income inequality are less likely to share open spaces $[26,36]$; residents may be less likely to use green spaces in such neighborhoods, reducing the positive effect of this environment. Both social capital and security also strengthened the positive association between urbanicity (i.e., population density) and mental health, while the Gini index magnitude was reduced. A possible explanation is that residents in areas with higher social capital and a safer environment are more likely to develop closer social ties, rather than having a "nodding" acquaintance with each other [24-27, 42, 49]. This could be the reason for the increased population density effect. Nevertheless, even with a higher population density, rather than having good relationships with each other, residents of neighborhoods with high income inequality are less likely to develop close social ties and may face more conflicts [26, 27]. This weakens the positive effect of population density. Finally, neighborhood-based social capital still strengthened the positive relationship between sports facilities and residents' mental health. A reasonable explanation is that people living in neighborhoods that have higher levels of social capital and safety are more willing to share facilities and participate in 
Table 3 Results of the multilevel regressions with interaction effects

\begin{tabular}{|c|c|c|c|c|c|c|}
\hline \multirow[t]{2}{*}{ DV: Logged CES-D score } & \multicolumn{2}{|l|}{ Model 2} & \multicolumn{2}{|l|}{ Model 3} & \multicolumn{2}{|l|}{ Model 4} \\
\hline & Coefficient & Standard error & Coefficient & Standard error & Coefficient & Standard error \\
\hline \multicolumn{7}{|l|}{ Natural environment of the neighborhood } \\
\hline Green space & $-0.045^{*}$ & 0.023 & $-0.039^{*}$ & 0.019 & $-0.047^{*}$ & 0.023 \\
\hline \multicolumn{7}{|l|}{ Built environment of the neighborhood } \\
\hline Urbanicity & $-0.046^{* *}$ & 0.015 & $-0.031^{*}$ & 0.015 & $-0.048^{* *}$ & 0.015 \\
\hline Sports facilities (ref: no) & -0.008 & 0.044 & -0.020 & 0.043 & -0.024 & 0.047 \\
\hline \multicolumn{7}{|l|}{ Social environment of the neighborhood } \\
\hline Social trust & $-0.400^{*}$ & 0.206 & $-0.402^{*}$ & 0.203 & $-0.838^{*}$ & 0.358 \\
\hline Social reciprocity & $-0.375^{* *}$ & 0.121 & $-0.396^{* *}$ & 0.118 & $-0.379^{*}$ & 0.129 \\
\hline Social group membership & $-0.405^{*}$ & 0.160 & $-0.363^{*}$ & 0.158 & $-0.501^{* *}$ & 0.165 \\
\hline Gini index of household income & 0.289 & 0.198 & 0.107 & 0.195 & $-0.910^{* *}$ & 0.213 \\
\hline Security & 0.381 & 0.219 & 0.0 .337 & 0.218 & -0101 & 0.477 \\
\hline \multicolumn{7}{|l|}{ Neighborhood-based interaction effects } \\
\hline Green space $\times$ social trust & $-0.343^{*}$ & 0.135 & & & & \\
\hline Green space $\times$ social reciprocity & $-0.413^{* *}$ & 0.128 & & & & \\
\hline Green space $\times$ social group membership & $-0.395^{*}$ & 0.164 & & & & \\
\hline Green space $\times$ Gini index of household income & $0.665^{* *}$ & 0.101 & & & & \\
\hline Green space $\times$ security & -0.346 & 0.320 & & & & \\
\hline Urbanicity $\times$ social trust & & & $-0.128^{* *}$ & 0.041 & & \\
\hline Urbanicity $\times$ social reciprocity & & & 0.089 & 0.058 & & \\
\hline Urbanicity $\times$ social group membership & & & $-0.277^{* *}$ & 0.054 & & \\
\hline Urbanicity $\times$ Gini index of household income & & & $0.218^{* *}$ & 0.071 & & \\
\hline Urbanicity $\times$ security & & & $-0.249^{*}$ & 0.097 & & \\
\hline Sports facilities (ref: no) $\times$ social trust & & & & & 0.267 & 0.440 \\
\hline Sports facilities (ref: no) $\times$ social reciprocity & & & & & $-0.455^{* *}$ & 0.078 \\
\hline Sports facilities (ref: no) $\times$ social group membership & & & & & $-0.426^{*}$ & 0.210 \\
\hline Sports facilities (ref: no) $\times$ Gini index of household income & & & & & $2.281^{*}$ & 0.151 \\
\hline Sports facilities (ref: no) $\times$ security & & & & & 0.481 & 0.527 \\
\hline Constant & $3.912^{* *}$ & 0.346 & $3.876^{* *}$ & 0.341 & $5.100^{* *}$ & 0.538 \\
\hline Var (constant) & $0.129^{* *}$ & & $0.123^{* *}$ & & $0.135^{* *}$ & \\
\hline Var (residual) & $1.071^{* *}$ & & $1.022^{* *}$ & & $1.059^{* *}$ & \\
\hline AIC & $60,505.86$ & & $59,552.09$ & & $60,295.20$ & \\
\hline
\end{tabular}

Significance level: ${ }^{*} p<0.05,{ }^{* *} p<0.01$. All continuous independent variables were mean centered. Models $2-4$ were adjusted for all covariates presented by Table 1

sports together, instead of guarding against each other $[26,27,43,49]$. On the contrary, residents in neighborhoods that have higher levels of income inequality may be less likely to share facilities or engage in physical activities together [26, 27]. This may weaken the positive effect of sports facilities.

The following limitations should be considered when interpreting our findings. First, restricted by data availability, our research design was cross-sectional and only reveals correlational, rather than causal, relationships. Second, neighborhoods in this study were defined as administrative units (i.e., residential committees and village committees), which may not be in line with people's experienced neighborhood [14]. This may mean that our results could be sensitive to the underlying scale and zoning of the analyses (also known as the modifiable areal unit problem). Third, due to privacy protection regulations, we were not able to obtain the exact coordinates of respondents' residential addresses, which would result in more accurate and objective exposure assessments. Fourth, some covariates such as physical activity may have potential mediating effect between greenspace and depression, but we only focused on the moderation effects and may ignore some potential mediation effects 
(for example, neighborhood social cohesion facilitation mediating the link between green space exposure and mental health) [50]. Fifth, since we mainly focused on the moderation effects, we set the relationship between environmental factors and depression to be linear, but the relationship between some environmental factors and depression may be non-linear. Last, the neighbourhood environment indicators in this study is from questionnaire. Future research should use more other source of data such as location-based big data [51-53]. Nevertheless, as one of the first Chinese studies to focus on environment-mental health associations, the present results contribute to the literature by providing novel, statistically sound, and robust empirical evidence for how broad environmental factors impact mental health outcomes.

\section{Conclusion}

The present study confirmed that the built, natural, and social environments within a neighborhood is associated with depressive symptoms among Chines residents, while also highlighting key moderation effects. The present results suggest that the neighborhood-based social environment moderates the associations between the quality of the built/natural environment and respondents' depressive symptoms. The present study was novel in that it also considered the interaction between different categories of neighborhood environmental factors. An interaction between the social environment strengthened the negative association between neighborhood green spaces, population density and respondents' depressive symptoms, while a more heterogeneous income level per neighborhood mitigated the negative association. Neighborhood social capital appeared to alleviate the health benefits of green space exposure, population density, and the availability of sports facilities on respondents' depressive symptoms, whereas income inequality within the neighborhood weakened any positive effects. We recommend that more research addressing the interactions between neighborhood environments be conducted in order to illuminate complex mental health-environment relationships.

\section{Abbreviations}

AIC: Akaike information criterion; CES-D: Center for Epidemiologic Studies Depression Scale; CLDS: China Labour-force Dynamics Survey; VIF: Variance inflation factors

\section{Acknowledgements \\ Data used in this study were derived from the China Labour-force Dynamics Survey (CLDS), conducted at Sun Yat-Sen University in Guangzhou, China. The opinions in this paper are those of the authors. The authors would like to thank the editor and the anonymous reviewers for their helpful and con- structive comments, which greatly improved the paper.}

\section{Authors' contributions}

All authors contributed to the study design. RW performed the statistical analyses. RW wrote the first draft of the manuscript with the help of $\mathrm{MH}$. RW, $\mathrm{MH}, \mathrm{DX}$ and $\mathrm{YL}$ revised the manuscript. All authors approved the final manuscript.

\section{Funding}

The authors are grateful for the research grants from the National Natural Science Foundation of China (No. 41320104001, No. 41501151, No. 41871140) and the Program for Guangdong Introducing Innovative and Enterpreneurial Teams (No.2017ZT07X355). The funders had no role in the study design (beyond pre-award feedback on the proposal), the collection, analysis, interpretation of data, and the writing-up of the manuscript.

\section{Availability of data and materials}

The dataset (questionnaire, individual and neighbourhood data) supporting the conclusions of this article are available in at http://css.sysu.edu.cn. To obtain more details regarding data, emails can be sent to the head of CLDS team [cssdata@mail.sysu.edu.cn].

\section{Ethics approval and consent to participate}

This study was a secondary analysis of the identified CLDS public data. The Ethics Committee of the Department of Sociology and social work in Sun Yat-Sen University granted the current study exemption from review. RW and $Y L$ received permission from the CLDS team to use this.

\section{Consent for publication}

Not applicable.

\section{Competing interests}

The authors declare that the research was conducted in the absence of any commercial or financial relationships that could be construed as a potential conflict of interest.

\section{Author details}

${ }^{1}$ School of Geography and Planning, Sun Yat-Sen University, Xingang Xi Road, Guangzhou 510275, China. ${ }^{2}$ Guangdong Key Laboratory for Urbanization and Geo-simulation, Sun Yat-Sen University, Xingang Xi Road, Guangzhou 510275, China. ${ }^{3}$ Department of Human Geography and Spatial Planning, Utrecht University, Utrecht, The Netherlands.

Received: 3 October 2018 Accepted: 17 June 2019

Published online: 05 July 2019

\section{References}

1. China health and retirement longitudinal study 2013. Secondary China health and retirement longitudinal study 2013. 2013. http://charls.pku.edu. cn/zh-CN. Accessed 25 Nov 2014.

2. Mair CF, Roux AVD, Galea S. Are neighborhood characteristics associated with depressive symptoms? A critical review. J Epidemiol Community Health. 2008:62:940-6.

3. Richardson R, Westley T, Gariépy G, Austin N, Nandi A. Neighborhood socioeconomic conditions and depression: a systematic review and metaanalysis. Soc Psychiatry Psychiatr Epidemiol. 2015;50(11):1641-56.

4. Gascon $M$, Triguero-Mas M, Martínez D, Dadvand P, Forns J, Plasència A, Nieuwenhuijsen MJ. Mental health benefits of long-term exposure to residential green and blue spaces: a systematic review. Int J Environ Res Public Health. 2015;12(4):4354-79.

5. Dzhambov A, Hartig T, Markevych I, Tilov B, Dimitrova D. Urban residential greenspace and mental health in youth: different approaches to testing multiple pathways yield different conclusions. Environ Res. 2018;160:47-59.

6. Dzhambov AM, Markevych I, Hartig T, Tilov B, Arabadzhiev Z, Stoyanov D, Gatseva P, Dimitrova DD. Multiple pathways link urban green-and bluespace to mental health in young adults. Environ Res. 2018;166:223-33.

7. Helbich M, Yao Y, Liu Y, Zhang J, Liu P, Wang R. Using deep learning to examine street view green and blue spaces and their associations with geriatric depression in Beijing, China. Environ Int. 2019;126:107-17.

8. Dzhambov AM, Markevych I, Tilov B, Arabadzhiev Z, Stoyanov D, Gatseva P, Dimitrova DD. Pathways linking residential noise and air pollution to mental ill-health in young adults. Environ Res. 2018;166:458-65.

9. Wang R, Liu Y, Xue D, Yao Y, Liu P, Helbich M. Cross-sectional associations between long-term exposure to particulate matter and depression in China: the mediating effects of sunlight, physical activity, and neighborly reciprocity. J Affect Disord. 2019;249:8-14.

10. Miles R, Coutts C, Mohamadi A. Neighborhood urban form, socia environment, and depression. J Urban Health. 2012;89(1):1-18. 
11. Wang R, Lu Y, Zhang J, Liu P, Yao Y, Liu Y. The relationship between visual enclosure for neighbourhood street walkability and elders' mental health in China: using street view images. J Transp Health. 2019;13:90-102.

12. Casper M. A definition of "soecial environment". Am J Public Health. 2001; 91:465.

13. Wang $R$, Xue D, Liu Y, Liu $P$, Chen $H$. The relationship between air pollution and depression in China: is neighbourhood social capital protective? Int J Environ Res Public Health. 2018;15(6):1160.

14. Helbich M. Toward dynamic urban environmental exposure assessments in mental health research. Environ Res. 2018;161:129-35.

15. Ah LS, Ju YJ, Eun LJ, Sun HI, Young NJ, Han KT, Euncheol P. The relationship between sports facility accessibility and physical activity among Korean adults. BMC Public Health. 2016;16(1):893.

16. Beyer KMM, Kaltenbach A, Szabo A, Bogar S, Nieto FJ, Malecki KM. Exposure to neighborhood green space and mental health: evidence from the survey of the health of Wisconsin. Int J Environ Res Public Health. 2014;11(3):3453.

17. Cramer V, Torgersen S, Kringlen E. Quality of life in a city: the effect of population eensity. Soc Indic Res. 2004;69(1):103-16.

18. Fan Y, Das KV, Chen Q. Neighborhood green, social support, physical activity, and stress: assessing the cumulative impact. Health Place. 2011; 17(6):1202-11.

19. Melis G, Gelormino E, Marra G, Ferracin E, Costa G. The effects of the urban built environment on mental health: a cohort study in a large northern Italian city. Int J Environ Res Public Health. 2015;12(11):14898-915|.

20. Lachowycz K, Jones AP. Towards a better understanding of the relationship between greenspace and health: development of a theoretical framework. Landsc Urban Plan. 2013;118(3):62-9.

21. Liu Y, Zhang F, Wu F, Liu Y, Li Z. The subjective wellbeing of migrants in Guangzhou, China: the impacts of the social and physical environment. Cities. 2017:60:333-42.

22. Maas J, Dillen SMEV, Verheij RA, Groenewegen PP. Social contacts as a possible mechanism behind the relation between green space and health. Health Place. 2009;15(2):586-95.

23. Regoeczi WC. Crowding in context: an examination of the differential responses of men and women to high-density living environments. J Health Soc Behav. 2008:49(3):254.

24. Groenewegen PP, Zock J-P, Spreeuwenberg P, Helbich M, Hoek G, Ruijsbroek A, Strak M, Verheij RA, Volker B, Waverijn G, Dijst M. Neighbourhood social and physical environment and general practitioner assessed morbidity. Health Place. 2018;49:68-84.

25. Helbich M, Klein N, Roberts H, Hagedoorn P, Groenewegen PP. More green space is related to less antidepressant prescription rates in the Netherlands: a Bayesian geoadditive quantile regression approach. Environ Res. 2018;166:290-7.

26. Kim D. Blues from the neighborhood? Neighborhood characteristics and depression. Epidemiol Rev. 2008;30(1):101-17.

27. Ross CE. Neighborhood disadvantage and adult depression. J Health Soc Behav. 2000:41(2):177-87.

28. Ard K, Colen C, Becerra M, Velez T. Two mechanisms: the role of social capital and industrial pollution exposure in explaining racial disparities in self-rated health. Int J Environ Res Public Health. 2016;13(10):1-16.

29. Radloff LS. The CES-D scale: a self-report depression scale for research in the general population. App IPsychol Meas. 1977;1(3):385-401.

30. Yang L, Jia CX, Qin P. Reliability and validity of the Center for Epidemiologic Studies Depression Scale (CES-D) among suicide attempters and comparison residents in rural China. BMC Psychiatry. 2015;15(1):76.

31. van den Berg M, Wendel-Vos W, van Poppel M, Kemper H, van Mechelen W, Maas J. Health benefits of green spaces in the living environment: a systematic review of epidemiological studies. Urban For Urban Green. 2015; 14(4):806-16.

32. Peen J, Schoevers RA, Beekman AT, Dekker J. The current status of urban-rura differences in psychiatric disorders. Acta Psychiatr Scand. 2010;121(2):84-93.

33. Mammen G, Faulkner G. Physical activity and the prevention of depression: a systematic review of prospective studies. Am J Prev Med. 2013;45(5):649-57.

34. Kawachi I, Kennedy BP, Glass R. Social capital and self-rated health: a contextual analysis. Am J Public Health. 1999;89(8):1187-93.

35. Wang $R$, Xue D, Liu Y, Chen H, Qiu Y. The relationship between urbanization and depression in China: the mediating role of neighborhood social capital. Int J Equity Health. 2018;17(1):105.

36. Niedzwiedz CL, Richardson EA, Tunstall H, Shortt NK, Mitchell RJ, Pearce JR. The relationship between wealth and loneliness among older people across Europe: is social participation protective. Prev Med. 2016;91:24-31.
37. Raudenbush SW, Bryk AS. Hierarchical linear models: applications and data analysis methods (Vol. 1): Sage; 2002.

38. Zhang W, Yang J, Ma L, Huang C. Factors affecting the use of urban green spaces for physical activities: views of young urban residents in Beijing. Urban For Urban Green. 2015;14(4):851-7.

39. You $\mathrm{H}$. Characterizing the inequalities in urban public green space provision in Shenzhen, China. Habitat Int. 2016;56:176-80.

40. Vlahov D, Galea S. Urbanization, urbanicity, and health. J Urban Health. 2002;79(1):S1-S12.

41. Caughy MO, O'Campo PJ, Muntaner $C$. When being alone might be better: neighborhood poverty, social capital, and child mental health. Soc Sci Med. 2003;57(2):227-37

42. Jones $R$, Heim D, Hunter S, Ellaway A. The relative influence of neighbourhood incivilities, cognitive social capital, club membership and individual characteristics on positive mental health. Health Place. 2014;28: 187-93.

43. Ziersch AM, Baum FE, Macdougall C, Putland C. Neighbourhood life and social capital: the implications for health. Soc Sci Med. 2005;60(1):71-86.

44. Feng Z, Vlachantoni A, Liu X, Jones K. Social trust, interpersonal trust and selfrated health in China: a multi-level study. Int J Equity Health. 2016;15(1):180

45. Meng T, Chen H. A multilevel analysis of social capital and self-rated health: evidence from China. Health Place. 2014:27(27):38-44.

46. Bakkeli NZ. Income inequality and health in China: a panel data analysis. Soc Sci Med. 2016:157:39-47.

47. Tan Z, Shi F, Zhang H, Li N, Xu Y, Liang Y. Household income, income inequality, and health-related quality of life measured by the EQ-5D in Shaanxi, China: a cross-sectional study. Int J Equity Health. 2018;17(1):32.

48. Wang SM, Dalal K. Safe communities in China as a strategy for injury prevention and safety promotion programmes in the era of rapid economic growth. J Community Health. 2013;38(1):205-14.

49. Burns JK, Tomita A. A multilevel analysis of association between neighborhood social capital and depression: evidence from the first south African national income dynamics study. J Affect Disord. 2013:144(1-2):101-5.

50. Wang R, Helbich M, Yao Y, Zhang J, Liu P, Liu Y. Urban greenery and menta wellbeing in adults: cross-sectional mediation analyses on multiple pathways across different greenery measures. arXiv preprint arXiv:1905. 04488, 2019

51. Boulos MNK, Peng G, VoPham T. An overview of GeoAl applications in health and healthcare. Int J Health Geogr. 2019:18:7.

52. Boulos MNK, Lu Z, Guerrero P, Jennett C, Steed A. From urban planning and emergency training to Pokémon go: applications of virtual reality GIS (VRGIS) and augmented reality GIS (ARGIS) in personal, public and environmental health. Int J Health Geogr. 2017;16:7.

53. Su S, Zhou H, Xu M, Ru H, Wang W, Weng M. Auditing street walkability and associated social inequalities for planning implications. J Transp Geogr. 2019;74:62-76.

\section{Publisher's Note}

Springer Nature remains neutral with regard to jurisdictional claims in published maps and institutional affiliations.

Ready to submit your research? Choose BMC and benefit from:

- fast, convenient online submission

- thorough peer review by experienced researchers in your field

- rapid publication on acceptance

- support for research data, including large and complex data types

- gold Open Access which fosters wider collaboration and increased citations

- maximum visibility for your research: over $100 \mathrm{M}$ website views per year

At BMC, research is always in progress.

Learn more biomedcentral.com/submission 